\title{
Effect of Compressive Stress on Ultrasonic Pulse Velocity
}

\author{
${ }^{1}$ Vishwajeet Surshetwar, ${ }^{2}$ Krishna Gattewar, ${ }^{3}$ Bhagyashree Wange, \\ ${ }^{4}$ Trupti Gavit, ${ }^{5}$ Mr. Ravi Ranade, ${ }^{6}$ Mrs. Prital G. Kalasur \\ ${ }^{1,2,3,4}$ Students of final year B.E. civil Engineering, \\ ${ }^{5}$ Construction Diagnostic Center, \\ ${ }^{6}$ Assistant Professor, \\ Dept. of Civil Engineering
}

\begin{abstract}
This paper presents a study on effect of incremental compressive stress in concrete on measured ultrasonic pulse velocity (UPV). In this we are going to study 80 number of cube samples which made from 8 different grades of mix proportion, which are M10,M 20, M30, M40, M50, M60, M70 \& M80. The test will conduct after 28 days of curing. The specimen will subjected to monotonic axial loading in stages until failure while UPV values will recorded. Changing in velocity of the pulse will correlated to increasing level of stress. Result will be interpreted on tables and graphs. We are expecting that the velocity of ultrasonic pulse will increase with increase in compressive stress.
\end{abstract}

Keywords: NDT - Non Destructive, UPV - Ultrasonic Pulse Velocity, Stress Factor, Compressive stress.

\section{INTRODUCTON}

Ultrasonic pulse velocity test is the non destructive test which is used to find out the integrity of the concrete already constructed/casted. In this test the approximate strength of concrete is measured by measuring the time required for ultrasonic longitudinal waves of pulse travel from one transmitting transducer to another receiving transducer. There was need for the present research to develop the testing method for evaluating the properties of concrete in structure, in relation to the in situ compression stress

A project involves casting of cubes and studies the variation between UPV and compressive stress. To do so we need to get basics components of concrete (cement, fine aggregate, coarse aggregate, water etc.). To get strength of M80 and M70, admixture like "PC base" is used.

\section{SCOPES AND OBJECTIVE}

The test is carried to examine the effect of compressive stress only in lateral direction. The aim of this test is to prove that increase in compressive stress has significant effect on ultrasonic pulse velocity value due to the progressive cracking during the compression test.

In India now a day this test is carried out to find out approx compressive stress of different structural components under different stress conditions as it is. Through this paper we wanted to find the correction factor to correct the readings taken in UPV test in order to give correct interpretation of the UPV test.

For the main aim, the following objectives are defined:

1) Determine design mix for different types of concrete used in the test.

2) Determine the effect of concrete grade on UPV without stress concrete.

3) Determine the ultrasonic pulse velocity in concrete with increase compressive stress

4)

\section{METHOD ADOPTED}

As this is the R\&D project hence method adopted is not the conventional one. To find fulfill the above mentioned objectives we need to follow the following stages
1) Design stage
2) Casting stage
3) Testing stage

\subsection{Design stage}

We need high grade concrete which can withstand with high stress so that we can test the variation of UPV at high level stress. The testing of materials is done in first stage of project and this is very first step of stage II.

\subsection{Casting stage}

We casted 40 no. of cubes in day and 40 no. in another day. After casting, on next day it is need to demould cubes and then place them for curing for 28 days. The temperature of curing water is maintained at room temperature.

\subsection{Testing stage}

After 28 days of curing the cubes are taken out from tank. The day before the testing all cubes are weighted and their dimensions (length, width, height etc) are noted.

Each cube is first placed in compression testing machine. The probes of ultrasonic pulse velocity are held in position manually on opposite surfaces of cubes (Direct method of UPV). Then load is applied on the cubes. The CTM is 
automatic so as it started once it stops only after crushing cube, hence there is need to take reading of UPV at particular instant and particular stress value.

\section{DISSCOSATION}

Now a day's UPV is popularly used as nondestructive test to know about integrity of the material and also the uniformity of the material. Its principle is that as higher the compactness of the material more will be the strength.

This test is used on the already constructed or existed buildings, towers, skyscrapers etc. As this test has huge variation of application. In this test first velocity of ultrasonic pulse is measured through the component. Then on the basis of velocity the strength is found out by the table given in IS code.

Ultrasonic pulse is longitudinal wave and we all know that velocity of longitudinal wave is increases as the material density increase. Such as velocity of longitudinal wave in gas is $350 \mathrm{~m} / \mathrm{s}$, in water is $1531 \mathrm{~m} / \mathrm{s}$, steel is $5960 \mathrm{~m} / \mathrm{s}$. Hence on the basis of velocity we are able to know the integrity as well as internal uniformity of the material.

The force applied on the body make deformation in it. This deformation creates distortions in form of micro cracks. These micro cracks developed due to the large stress. The components we are testing are also under the tremendous stress. So due to which micro cracks already present there as soon as the load is given. In IS code clause 6.4 [ IS13311 (Part1 ):1992 - Non-destructive testing of concrete ] they have mentioned that it causes negligible effect on the velocity of the ultrasonic pulse. But as we observed above they significantly affects the velocity

Hence to minimize this error we are introducing new methodology to find correct velocity of ultrasonic pulse

\section{OBERVATIONS}

As all tests are over we observed that velocity is continuously dropping as mono axial compressive stress is increasing. To make it applicable for any the component we have taken stress. The graph is plotted between stress and velocity.

While increasing the stress the value of UPV affects significantly. This is because as stress increases the micro cracking increases this micro cracks are filled with air. Hence the ultrasonic pulse travels through rarer medium. Hence its velocity decreases.

\section{Stress vs velocity : M10}

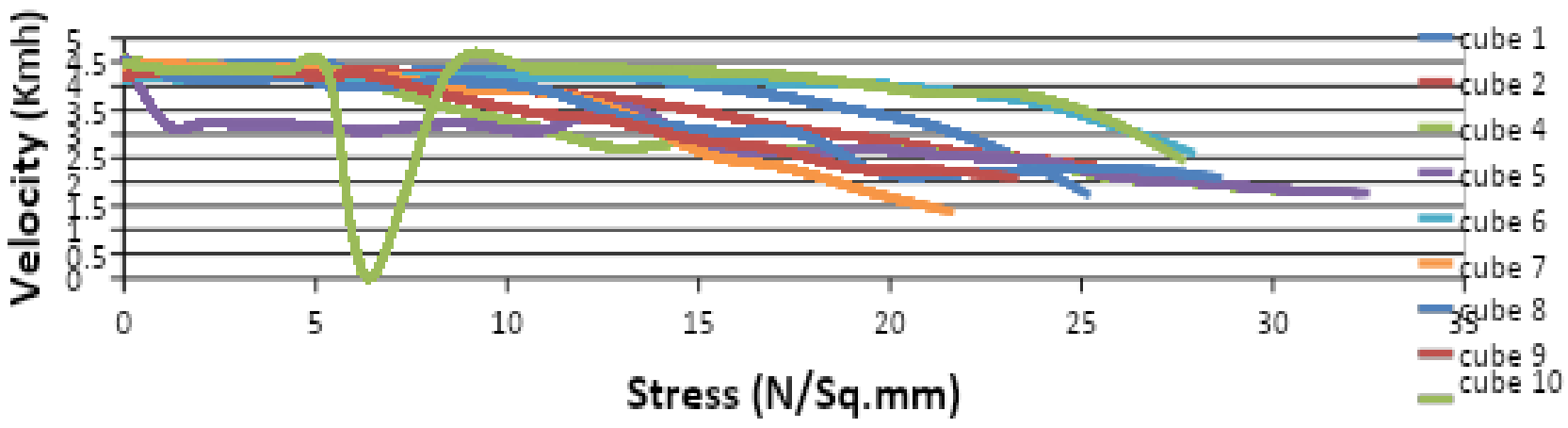

Figure No. 3: Stress VS Velocity: M10

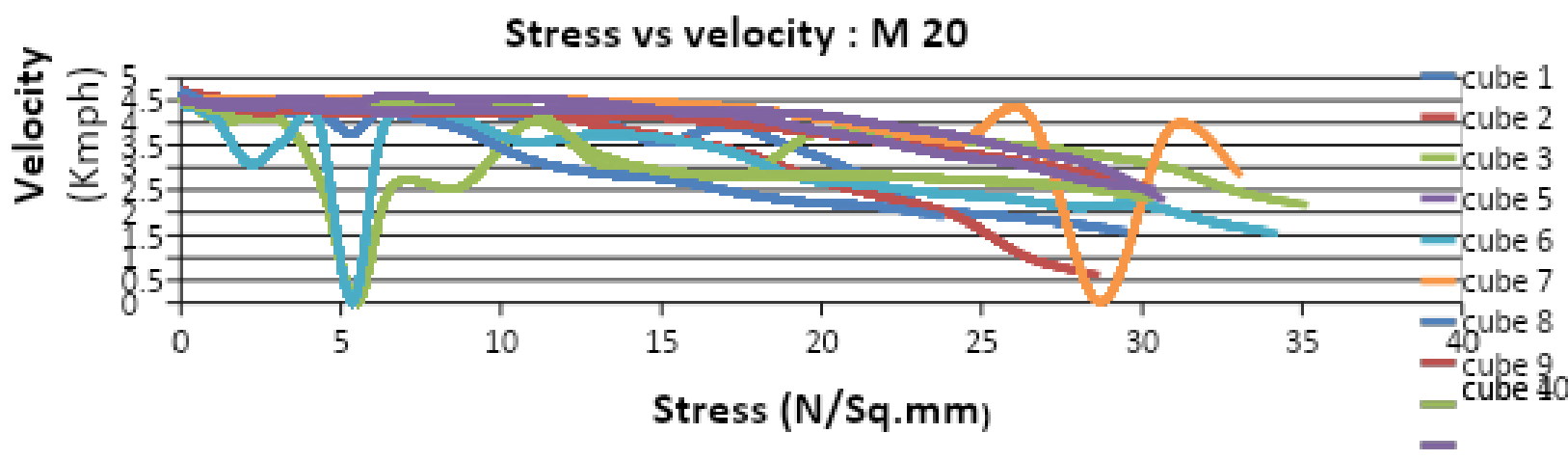

Figure No. 4: Stress VS Velocity: M20 


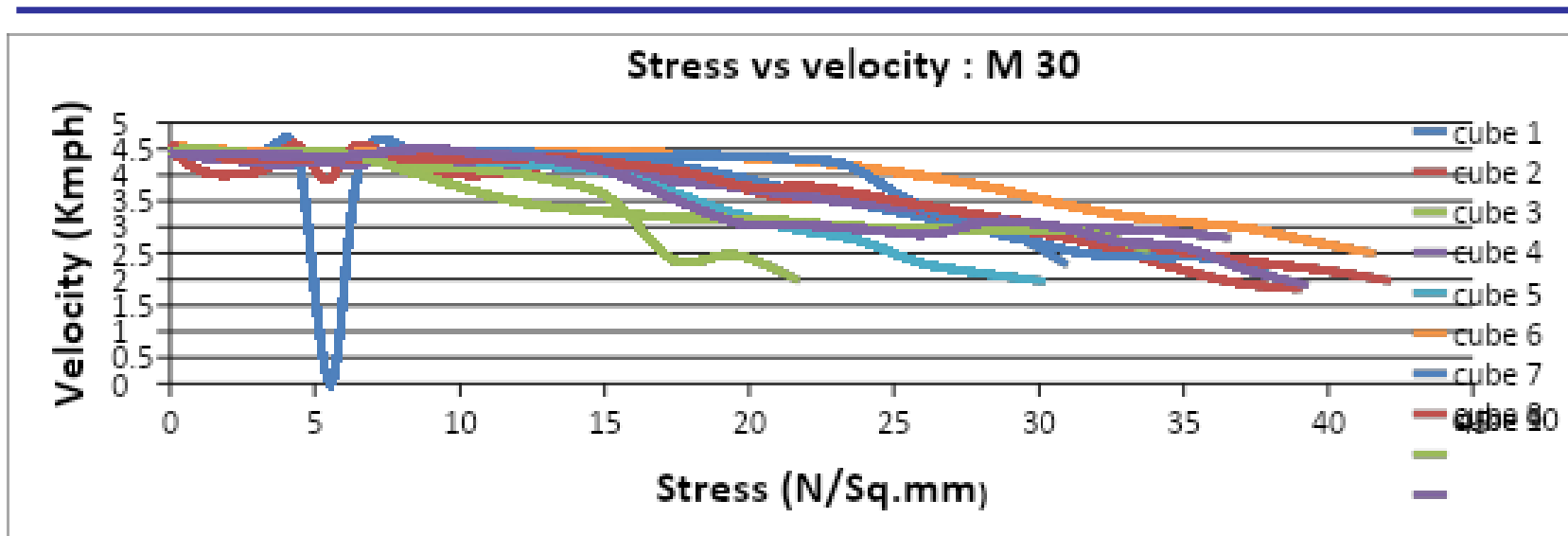

Figure No. 5: Stress VS Velocity: M30

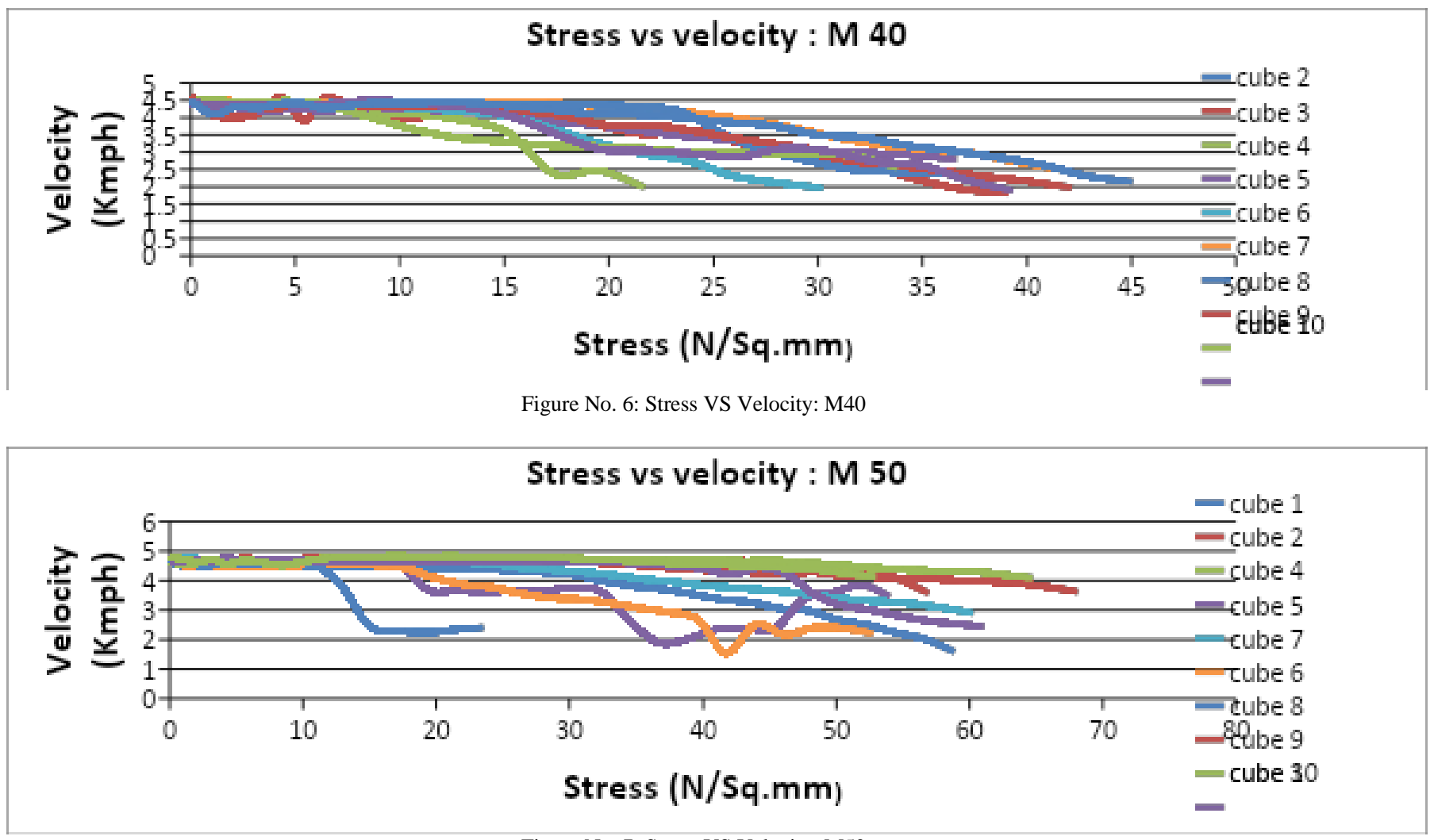

Figure No. 7: Stress VS Velocity: M50

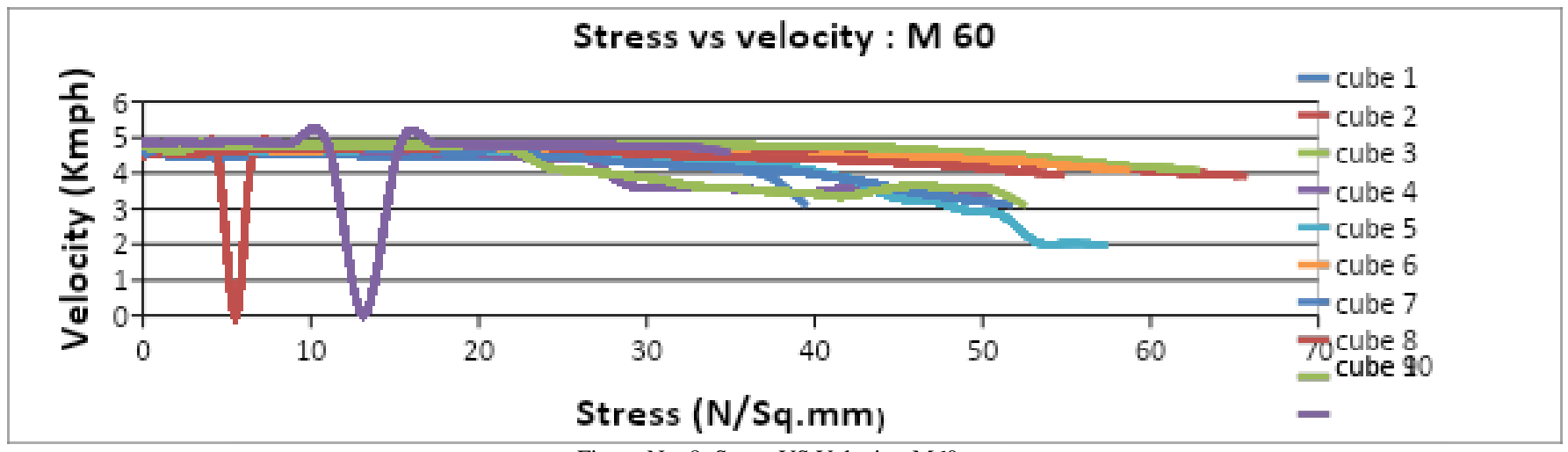

Figure No. 8: Stress VS Velocity: M60 


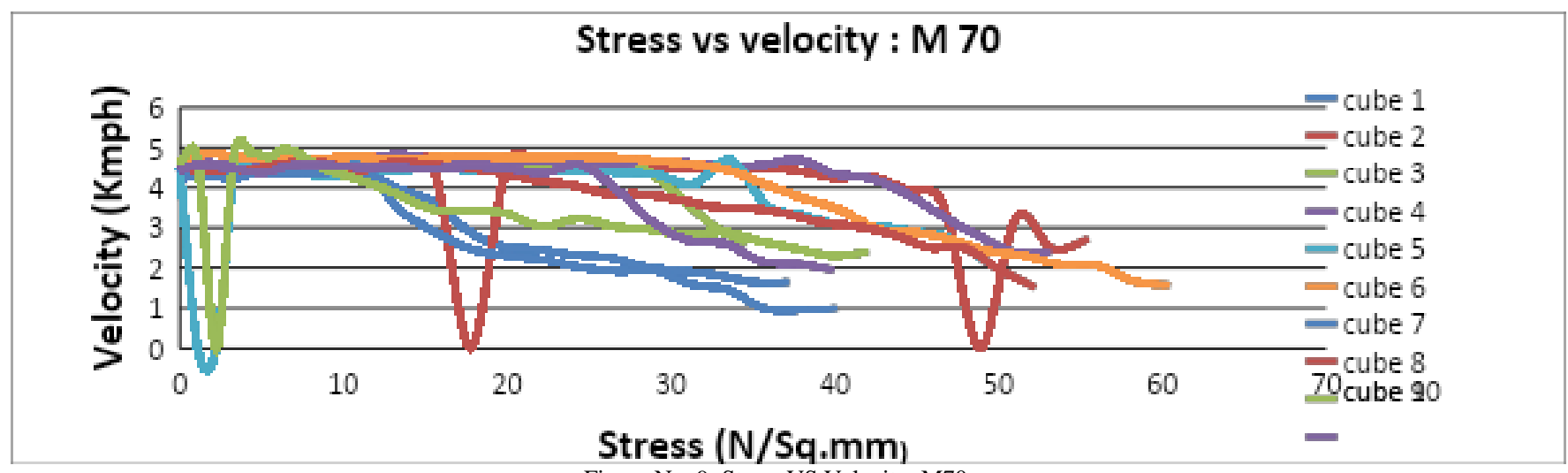

Figure No. 9: Stress VS Velocity: M70

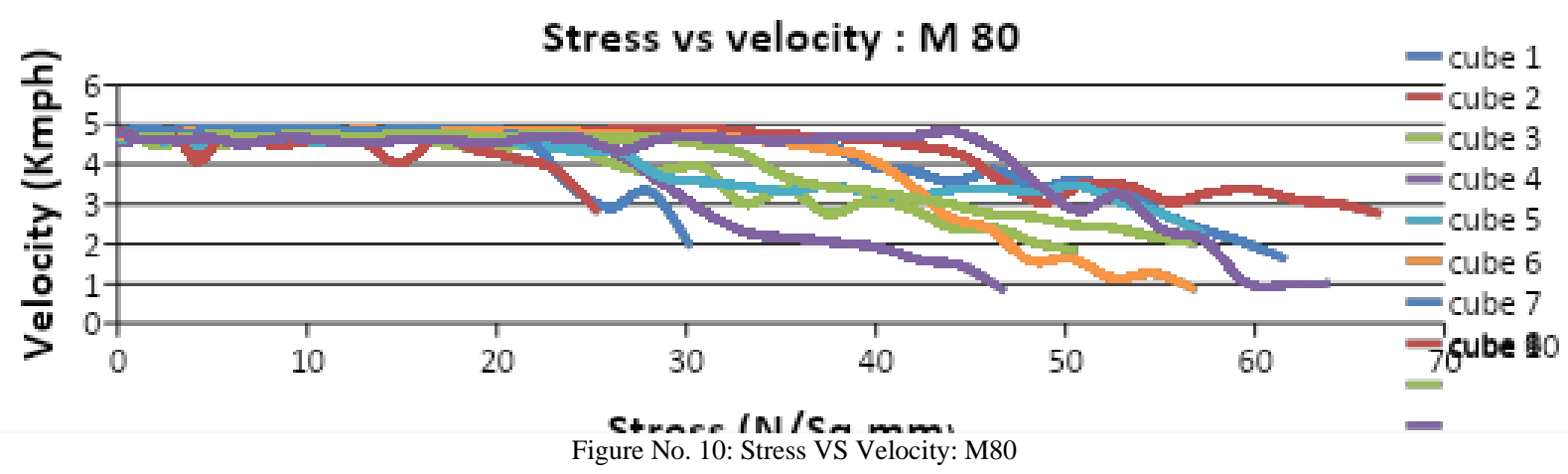

6. RESULTS

Results are in the form of graph of stress Vs stress factor. On the basis of observations we got we calculated the stress factor which is nothing but the ratio of velocity of ultrasonic pulse at zero stress to the velocity of ultrasonic pulse at certain value of stress.

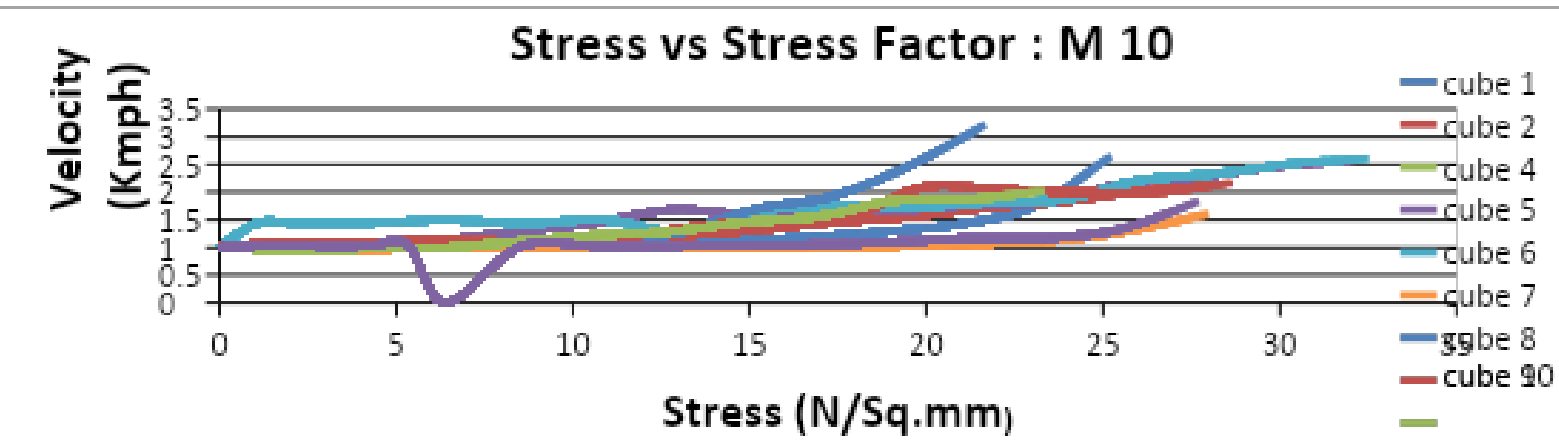

Figure No. 11: Stress VS Stress Factor: M10

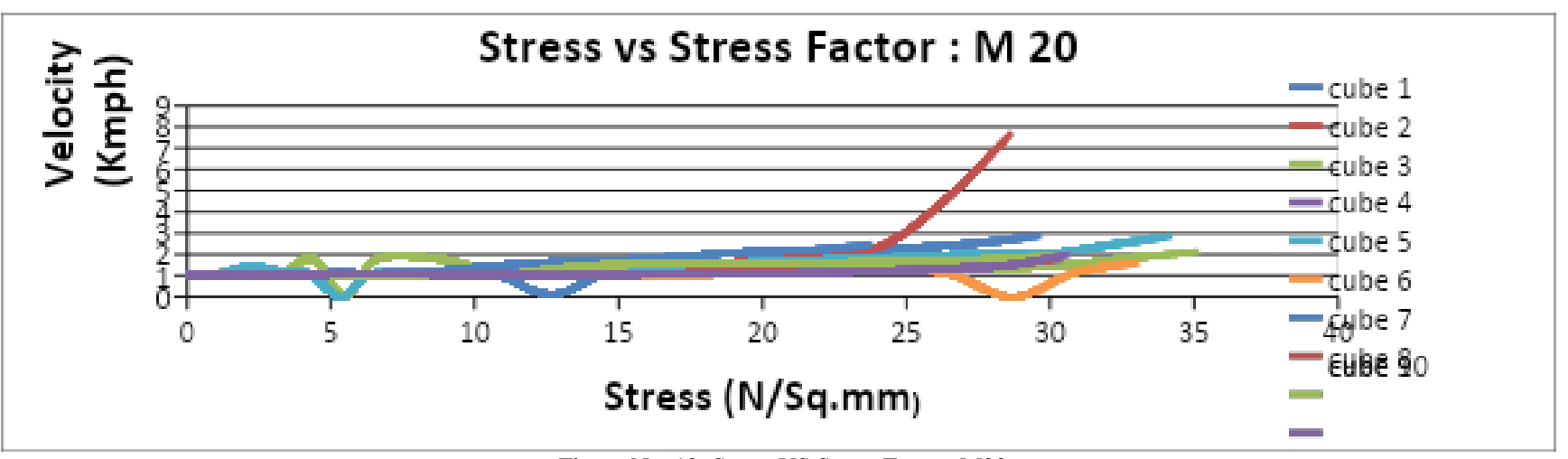

Figure No. 12: Stress VS Stress Factor: M20 

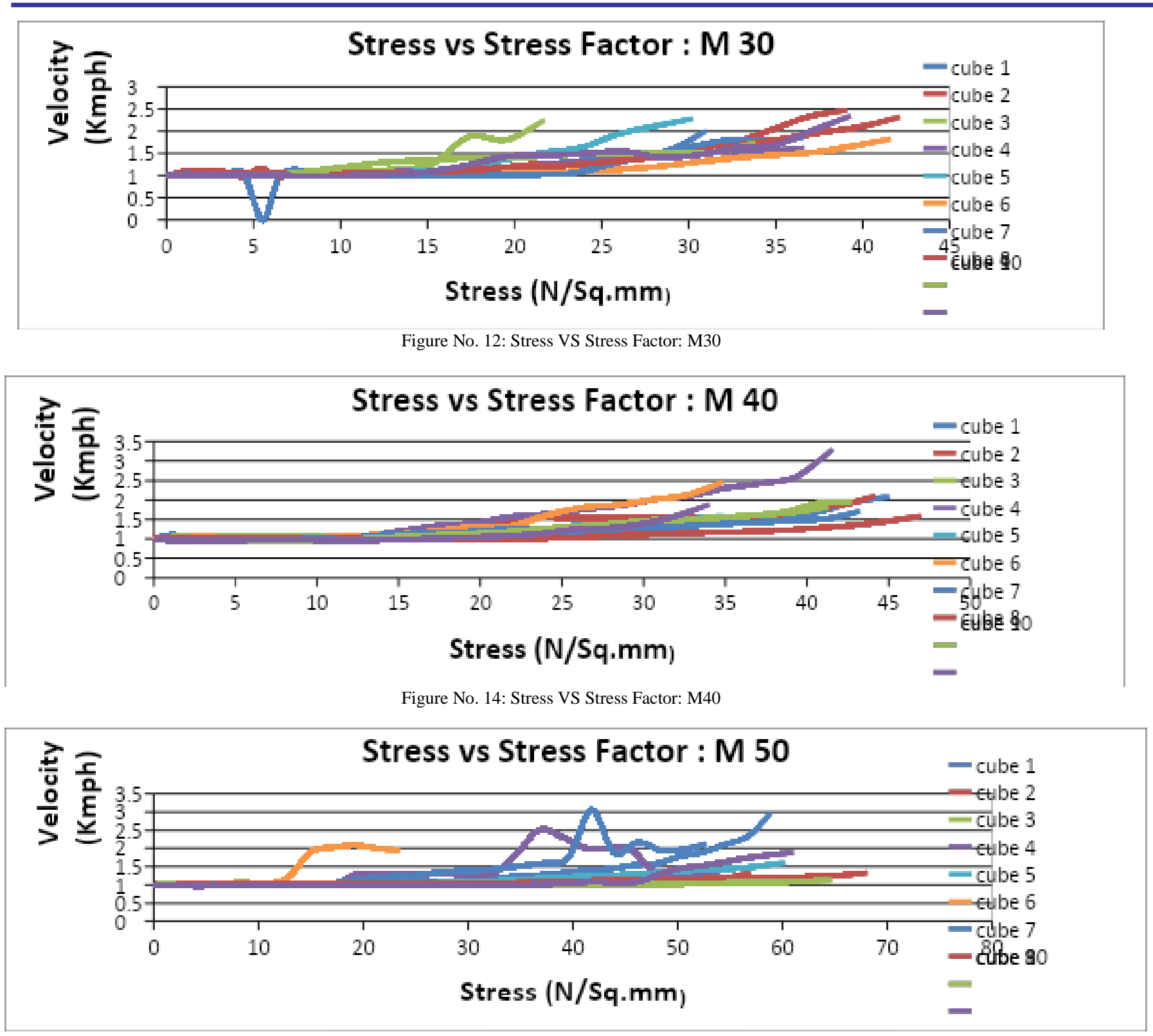

Figure No. F15: Stress VS Stress Factor: M50

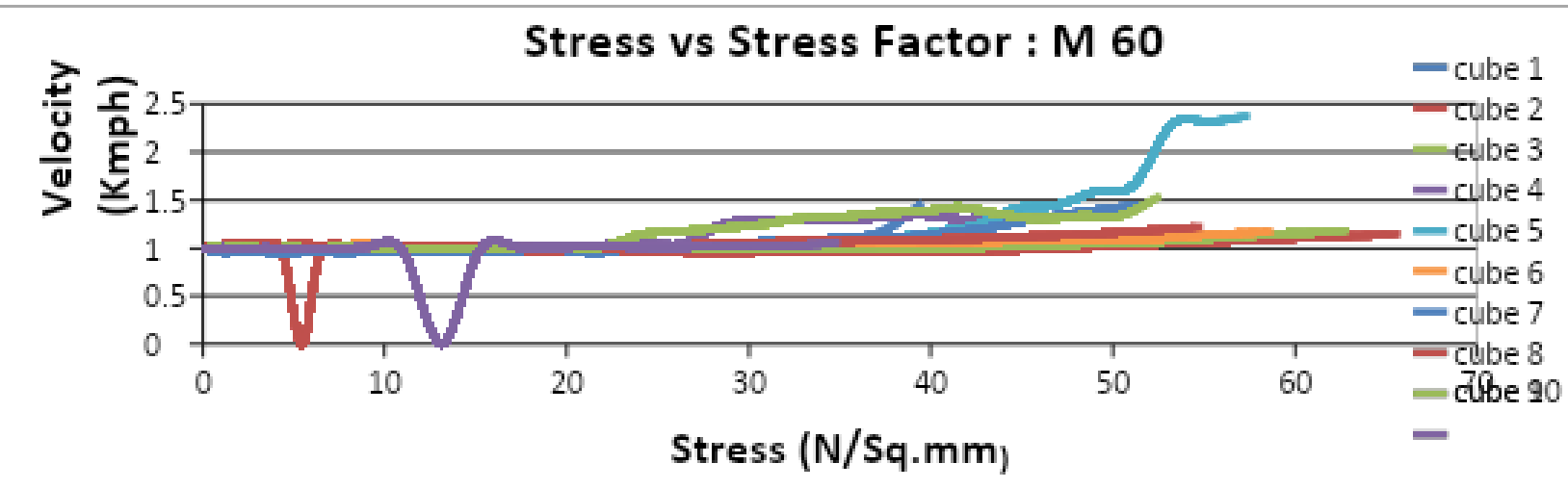

Figure No. 16: Stress VS Stress Factor: M60 


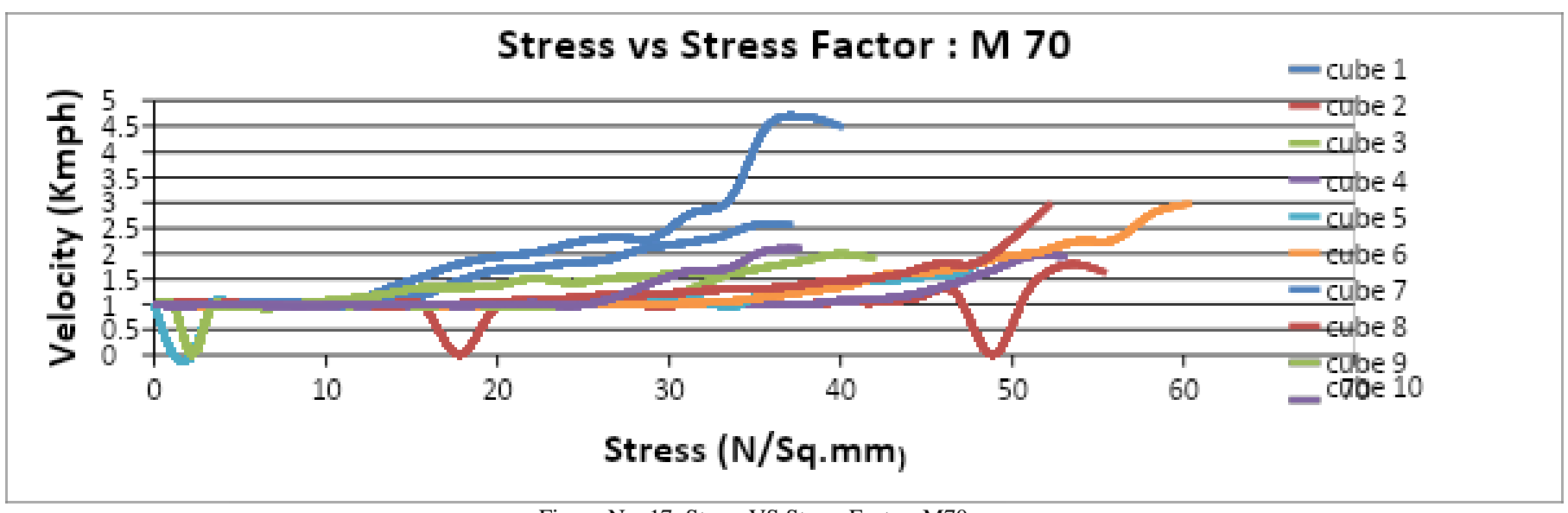

Figure No. 17: Stress VS Stress Factor: M70

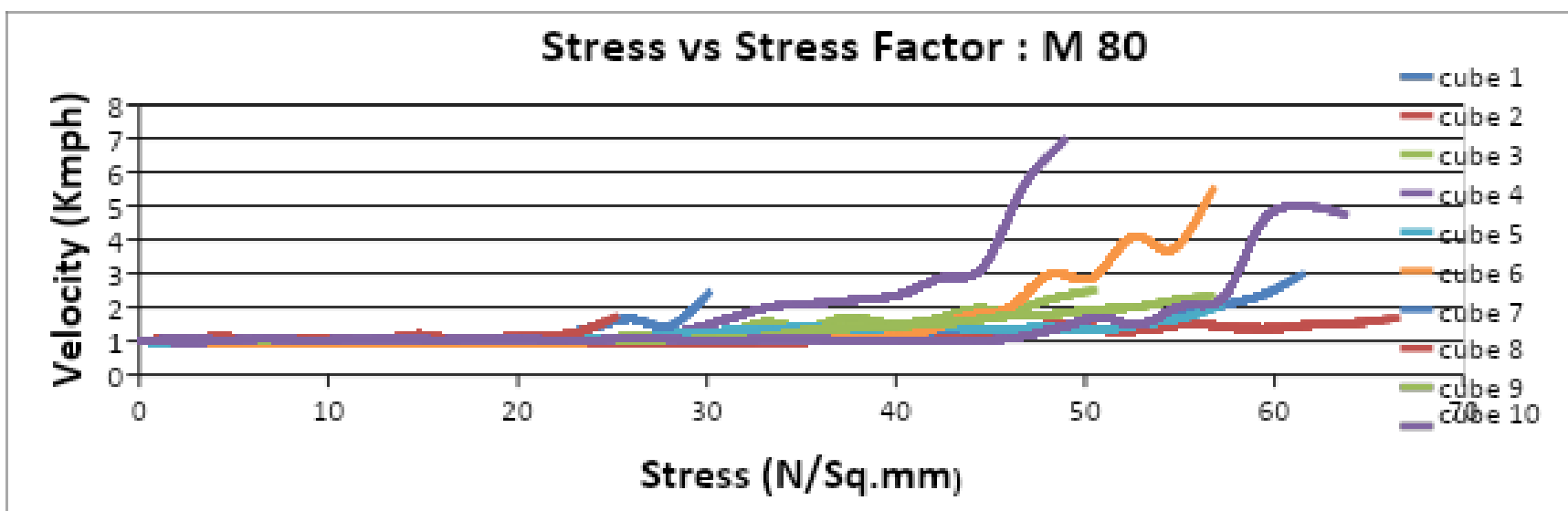

Figure No. 18: Stress VS Stress Factor: M80

\section{CONCLUSION}

On the basis of results we got we are drawing some conclusions below

1] As compressive stress increases on the component the UPV decreases.

2] The decrease in UPV is function of both stress and micro cracking.

3] To filter out this we need some new way to find the UPV at stress free condition.

\section{NEW METHODOLOGY}

1) Correct velocity

2) Stress factor

\section{1] Correct velocity:}

It means that the velocity of ultrasonic pulse through the component when it not under the influence of stress. This is the need that we have to find, because at zero stress there is no micro cracking has been done. This correct velocity is only one which gives us the true strength of component.

\section{2] Stress factor:}

The stress factor is nothing but the ratio of the velocity of ultrasonic pulse through the component at zero stress to the velocity of the ultrasonic pulse through component at particular stress. These stress factor is varies on the stress applied on the component.

Now on the basis of the results achieved the method to correct the velocity is as below

Step 1: Calculate the velocity of ultrasonic pulse through the component. Assume it as V1.

Step 2: Also calculate the value of stress on the component in direction perpendicular to the velocity measured (c/s of member).

Step 3:

Then go through the graphs given in results and find out the stress Factor for the particular stress according to the grade of concrete.

\section{Step 4:}

We know the stress factor is 


$$
\text { Stress Factor }=\frac{\text { correct velocity }(V 1)}{\text { velocity at perticular stress }}
$$

In above equation only unknown is UPV at zero stress i.e. correct velocity (V1). So from this we can find out UPV through component when it is stress free. With the help of this correct velocity we can say about is integrity, internal uniformity as well as predict the actual strength of the concrete.

\section{ACKNOWLEDGEMENT}

This study was supported by the Dr. D. Y. Patil college of Engineering, Akurdi and also by the CDC, Karve Road, Pune.

\section{REFERANCES}

[1] IS13311 (Part1 ):1992 - Non-destructive testing of concrete - Methods of test Part 1 ultrasonic pulse velocity.

[2] "Belaribi Hassiba, Mellas Mekki, Rahmani Farid [2017-2018] - The Relation Between Compressive Strength And Ultrasonic Pulse Velocity Concrete With Fiber Exposed To High Temperatures.

[3] Mahdi Shariati, Nor Hafizah Ramli-Sulong, Mohammad Mehdi Arabnejad K. H.,PayamShafigh and Hamid Sinaei [2011] - Assessing the strength of reinforced concrete structures through Ultrasonic Pulse Velocity and Schmidt Rebound Hammer tests

[4] Mohammadreza Hamidian, MashdiShariati, M.M.Arabnejad and Hamid Sansei [2011]-Assessment of high strength and light weight aggregate concrete properties using ultra sonic pulse velocity technique.

[5] Chong Chooi Yeng[2010] - The effect of compressive stress in concrete on ultrasonic pulse velocity.

[6] Internet 